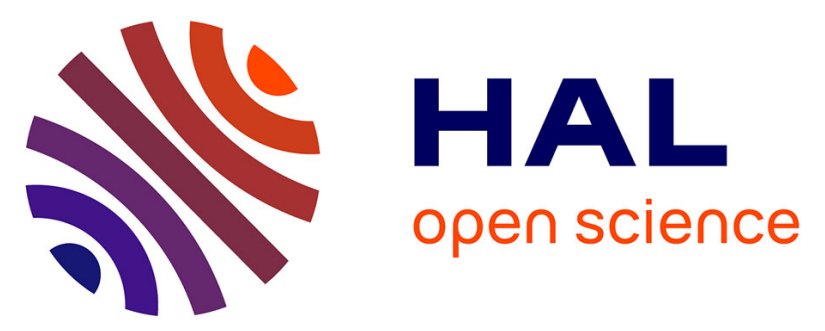

\title{
Ising-type Magnetic Anisotropy and Slow Relaxation of the Magnetization in Four-Coordinate Amido-Pyridine FeII Complexes
}

\author{
C. Gunnar Werncke, Mohammed-Amine Bouammali, Julie Baumard, Nicolas \\ Suaud, Cyril Martins, Nathalie Guihéry, Laure Vendier, Jianxia Zheng, \\ Jean-Baptiste Sortais, Christophe Darcel, et al.
}

\section{To cite this version:}

C. Gunnar Werncke, Mohammed-Amine Bouammali, Julie Baumard, Nicolas Suaud, Cyril Martins, et al.. Ising-type Magnetic Anisotropy and Slow Relaxation of the Magnetization in FourCoordinate Amido-Pyridine FeII Complexes. Inorganic Chemistry, 2016, 55 (21), pp.10968-10977. 10.1021/acs.inorgchem.6b01512 . hal-01413205

\section{HAL Id: hal-01413205 https://hal.science/hal-01413205}

Submitted on 13 Mar 2017

HAL is a multi-disciplinary open access archive for the deposit and dissemination of scientific research documents, whether they are published or not. The documents may come from teaching and research institutions in France or abroad, or from public or private research centers.
L'archive ouverte pluridisciplinaire HAL, est destinée au dépôt et à la diffusion de documents scientifiques de niveau recherche, publiés ou non, émanant des établissements d'enseignement et de recherche français ou étrangers, des laboratoires publics ou privés. 


\title{
Ising-Type Magnetic Anisotropy and Slow Relaxation of the Magnetization in Four-
}

\section{Coordinate Amido-Pyridine Fe ${ }^{\mathrm{II}}$ Complexes}

\author{
C. Gunnar Werncke, ${ }^{\dagger, t}$ Mohammed-Amine Bouammali, ${ }^{\#}$ Julie Baumard, ${ }^{\#}$ Nicolas Suaud, \\ Cyril Martins, ${ }^{\#}$ Nathalie Guihéry, ${ }^{* \#}$ Laure Vendier, ${ }^{\dagger, t}$ Jianxia Zheng, ${ }^{\S}$ Jean-Baptiste Sortais, ${ }^{\S}$ \\ Christophe Darcel,,$^{\S}$ Sylviane Sabo-Etienne, ${ }^{\dagger,+}$ Jean-Pascal Sutter, ${ }^{\dagger+\neq}$ Sébastien Bontemps, ${ }^{*+,+\neq}$ \\ Céline Pichon ${ }^{* t, t}$
}

${ }^{\dagger}$ CNRS, LCC, 205 route de Narbonne, F-31077 Toulouse, France.

$\$$ Université de Toulouse, UPS, INPT, LCC, F-31007 Toulouse, France.

\# LCPQ, Université de Toulouse III, 118 route de Narbonne, F-31062 Toulouse, France.

$\S$ Institut des Sciences Chimiques de Rennes, UMR 6226 CNRS - Université de Rennes 1, Team Organometallics: Materials and Catalysis, Centre for Catalysis and Green Chemistry, Campus de Beaulieu, 263 av. du Général Leclerc, F-35042 Rennes Cedex, France.

e-mail : celine.pichon@1cc-toulouse.fr, nathalie.guihery@irsamc.ups-tlse.fr, sebastien.bontemps@1cc-toulouse.fr 
Abstract. A family of four-coordinate $\mathrm{Fe}^{\mathrm{II}}$ complexes formed with $N, N^{\prime}$-chelating amidopyridine ligands has been synthesized and their magnetic properties investigated. These distorted tetrahedral complexes exhibit significant magnetic anisotropy with Zero-Field Splitting parameter $D$ ranging between -17 and $-12 \mathrm{~cm}^{-1}$. Ab initio calculations enabled to identify the structural factors which control the nature of the magnetic anisotropy in these complexes and to rationalize the variation of $D$ between the three complexes. It is shown that a reduced N-Fe-N angle involving the chelating nitrogen atoms of the ligands is at the origin of the negative $D$ value and that the torsion between the two N-Fe-N planes imposed by steric hindrances further increases the $|D|$ value. Field-induced slow relaxation of magnetization was observed for the three compounds and a SMM behavior with an energy barrier for magnetization flipping $\left(U_{\text {eff }}\right)$ of $27 \mathrm{~cm}^{-1}$ could be evidenced for one of them.

\section{INTRODUCTION.}

Slow relaxation of magnetization at the molecular scale was initially discovered in the complex $\left[\mathrm{Mn}_{12} \mathrm{O}_{12}(\mathrm{OAc})_{16}\left(\mathrm{H}_{2} \mathrm{O}\right)_{4}\right] .{ }^{1}$ This seminal work initiated active research on coordination complexes displaying such a unique magnetic phenomenon. In these so-called Single-Molecule Magnets (SMMs), each individual nano-magnet exhibits a magnetic hysteresis in the magnetization versus field curve and displays slow relaxation of the magnetization when removing the external field at low temperatures. This molecular magnetic bistability arises from a splitting of the $\mathrm{M}_{\mathrm{s}}$ components of the ground spin state $S$ due to both relativistic effects and a lowering of the ligand-field-induced symmetry. In the absence of magnetic field, the low energy spectrum presents an energy barrier between the various $M_{s}$ components with a degenerate ground state corresponding to the $+\mathrm{M}_{\mathrm{s}}$ and $-\mathrm{M}_{\mathrm{s}}$ components, i.e. with two different magnetization orientations. This phenomenon is therefore called Zero- 
Field Splitting (ZFS) and is characterized with two parameters: the axial parameter $D$ which by convention is negative when the largest $\left|\mathrm{M}_{\mathrm{s}}\right|$ components are the lowest in energy and the rhombic parameter $E$ which mixes the various $\mathrm{M}_{\mathrm{s}}$ components and is therefore responsible for tunneling. The height of the energy barrier $\Delta$ is given by $\Delta=D \cdot S^{2}$ for systems with integer spin ground states $(S)$ and $\Delta=D \cdot\left(S^{2}-1 / 4\right)$ for systems with half-integer spin ground states.

In 2010, the first report of slow relaxation of the magnetization in a mononuclear trigonal pyramidal $\mathrm{Fe}^{\mathrm{II}}$ complex ${ }^{2}$ fueled the interest for single-ion transition metal complexes. These are indeed the simplest systems to exhibit SMM behaviors provided they possess substantial magnetic anisotropy and, ideally, uni-axial (i.e. Ising-type) anisotropy characterized by a negative $D$ value. Interestingly, control of the coordination sphere (geometry, symmetry, ligand field) and relevant electronic configuration for the metal ion allows reaching significant magnetic anisotropy. ${ }^{3}$ For instance, weak ligand fields resulting from low coordination numbers are favorable parameters for large magnetic anisotropy in $3 \mathrm{~d}$ ions because i) orbital angular momentum is stronger and ii) second-order contribution of SpinOrbit Coupling (SOC) is enhanced when the energetic splitting between the ground state and first excited states is reduced.

Following the report by Freedman et al., several tetracoordinated $\mathrm{Fe}^{\mathrm{II}}$ complexes have been reported to exhibit magnetic anisotropy with $D$ parameters spanning from positive to strongly negative values (Table 1). ${ }^{2.4}$ Although the most negative $D$ has been found for $\mathrm{Fe}^{\mathrm{II}}$ in trigonal pyramid surrounding, the variety of geometries and nature of ligand systems preclude easy comparison and thus convincing rationalization for the $D$ values (Table SI1).

To provide further insights into the role of geometrical parameters on the anisotropy of four-coordinate $\mathrm{Fe}^{\mathrm{II}}$ compounds, we synthesized a new family of complexes formed with chelating amido-pyridine ligands (Scheme 1). ${ }^{5}$ In these complexes, the metal center has similar coordination surrounding but exhibit distinct distorted tetrahedral coordination 
polyhedra. Interestingly, their $D$ parameter was found to range from -17 to $-12 \mathrm{~cm}^{-1}$. In-depth theoretical investigations were decisive in identifying the geometrical distortions involved in the observed variation of $D$ values.

Table 1. Selected examples of magnetic anisotropy parameter $(D)$ in distorted four-coordinate $\mathrm{Fe}^{\mathrm{II}}$ complexes reported in the literature.

\begin{tabular}{|c|c|c|c|}
\hline Compound $^{\mathrm{a}}$ & Geometry & $D\left(\mathrm{~cm}^{-1}\right)$ & Ref. \\
\hline$\left[\mathrm{Fe}\left(\mathrm{CF}_{3}-\mathrm{ONO}\right) \mathrm{Cl}\right]$ & $\begin{array}{l}\text { Square } \\
\text { planar }\end{array}$ & 17.4 & 6 \\
\hline$\left[\mathrm{Fe}\left(\mathrm{Bc}^{\mathrm{t} B u}\right)_{2}\right]$ & Tetrahedral & -10.74 & $4 \mathrm{c}$ \\
\hline $\begin{array}{l}{\left[\mathrm{Fe}\left(\mathrm{N}\left(\mathrm{SiMe}_{3}\right)_{2}\right)_{2}\right.} \\
(\mathrm{depe})]\end{array}$ & Tetrahedral & +4.1 & $4 d$ \\
\hline$\left[\mathrm{Fe}\left(\mathrm{C}_{3} \mathrm{~S}_{5}\right)_{2}\right]\left(\mathrm{NBu}_{4}\right)_{2}$ & Tetrahedral & $+5.61(9)$ & $4 \mathrm{a}$ \\
\hline $\mathrm{Na}\left[\left(\mathrm{tpa}^{\mathrm{t}-\mathrm{Bu}}\right) \mathrm{Fe}\right]$ & Trigonal & -48 & 2 \\
\hline THF & pyramidal & & \\
\hline $\mathrm{K}\left[\left(\mathrm{tpa}^{\mathrm{Mes}}\right) \mathrm{Fe}\right] \cdot 2 \mathrm{DME}$ & $\begin{array}{l}\text { Trigonal } \\
\text { pyramidal }\end{array}$ & $-44(4)$ & 2 \\
\hline $\mathrm{K}\left[\left(\right.\right.$ tpa $\left.\left.^{\text {Trip }}\right) \mathrm{Fe}\right] \cdot 3 \mathrm{DME}$ & $\begin{array}{l}\text { Trigonal } \\
\text { pyramidal }\end{array}$ & $-30(2)$ & 2 \\
\hline $\mathrm{Na}\left[\left(\operatorname{tpa}^{\mathrm{Ph}}\right) \mathrm{Fe}\right] \cdot 3 \mathrm{DME}$ & $\begin{array}{l}\text { Trigonal } \\
\text { pyramidal }\end{array}$ & $-26(2)$ & 2 \\
\hline $\mathrm{K}\left[\left(\mathrm{tpa}^{\mathrm{DFP}}\right) \mathrm{Fe}\right] \cdot 2 \mathrm{DME}$ & $\begin{array}{l}\text { Trigonal } \\
\text { pyramidal }\end{array}$ & -6.2 & 2 \\
\hline
\end{tabular}

a $\mathrm{Bc}^{\mathrm{t} B u}=$ bis(3-tert-butylimidazol-2-ylidene)borate; $\quad\left[\mathrm{CF}_{3}\right.$-ONO $\mathrm{H}_{3}=2,2^{\prime}$-(azanediylbis(2,1phenylene) $)$ bis(1,1,1,3,3,3-hexafluropropan-2-ol); tpa ${ }^{\text {DFP }}=$ tris(5-2,6-difluorophenyl-pyrrol-2-yl)methyl)amine; tpa $^{\text {Mes }}=$ tris(5-mesityl-pyrrol-2-yl)methyl)amine; tpa $^{\text {Ph }}=$ tris(5-phenyl-pyrrol-2-yl)methyl)amine; tpa $^{\mathrm{t}-\mathrm{Bu}}=$ tris $(5-$ tert-butyl-pyrrol-2-yl)methyl)amine.

\section{Experimental Section.}

General Considerations. All manipulations were carried out in a glove-box or using Schlenk-type techniques under a dry argon atmosphere. Solvents were dried using a MBraun solvent purification system and stored over $4 \AA$ molecular sieves. The ${ }^{1} \mathrm{H}$ NMR spectra were recorded on a Bruker AV400 NMR spectrometer. Chemical shifts are reported in ppm relative to the residual proton of $\mathrm{C}_{6} \mathrm{D}_{6}(7.15 \mathrm{ppm})$. IR measurements were conducted on a Bruker Alpha ATR-IR spectrometer. Elemental analyses were performed by the internal service of the Laboratoire de Chimie de Coordination, Toulouse. It is worth mentioning that several 
attempts have been conducted in elemental analyses but the extreme sensitivity of the compounds precluded better results. $\mathrm{NBu}_{4} \mathrm{PF}_{6}$ for cyclovoltammetry was dried overnight in vacuo at $100{ }^{\circ} \mathrm{C}$. Solution magnetic susceptibilities were determined by the Evans method. ${ }^{7}$ $\mathrm{Fe}\left(\mathrm{N}\left(\mathrm{SiMe}_{3}\right)_{2}\right)_{2}, \mathrm{HN} 2_{\text {mes, }}, \mathrm{HN} 2_{\text {Dipp }}$ and $\mathrm{H}_{2} \mathrm{~N} 3_{\text {Dipp }}$ were prepared according to literature procedures. $^{8}$

\section{Syntheses of complexes 1-3.}

$\mathrm{Fe}\left(\mathrm{N} 2{ }_{\mathrm{mes}}\right)$, 1. To a solution of 2-[(mesitylamino)methyl]pyridine (HN2 ${ }_{\mathrm{mes}}, 155 \mathrm{mg}, 0.68$ mmol, 1 equiv. $)$ in pentane $(5 \mathrm{~mL})$ was added $\mathrm{Fe}\left(\mathrm{N}\left(\mathrm{SiMe}_{3}\right)_{2}\right)_{2},(125 \mathrm{mg}, 0.34 \mathrm{mmol}, 0.5$ equiv.) dissolved in $2 \mathrm{~mL}$ of pentane at room temperature, resulting in an immediate color change to red and precipitation after 1 minute. After 15 min. of stirring stirring at the same temperature, the solution was removed by filtration and the residue dried in vacuo to yield $130 \mathrm{mg}$ of $1(0.26 \mathrm{mmol}, 76 \%)$ as a bright red solid. ${ }^{1} \mathrm{H} \mathrm{NMR}\left(400.1 \mathrm{MHz}, \mathrm{C}_{7} \mathrm{D}_{8}, 298 \mathrm{~K}\right) \delta=$ 77.6, 44.38, 42.80, 40.40, 39.96, 22.05; IR (ATR, $\left.\mathrm{cm}^{-1}\right)=3306(\mathrm{vw}), 2982(\mathrm{w}), 2938(\mathrm{vw})$, 2906 (vw), 2744 (m), 2668 (vw), 1599 (w), 1560 (w), 1476 (s), 1435 (s), 1364 (vw), 1343 (m), 1297 (m), 1235 (vs), 1146 (s), 1102 (w), 1073 (s), 1043 (s), 949 (m), 886 (m), 846 (s), $801(\mathrm{~m}), 750$ (vs), 719 (s), 619 (m), 532 (s), 469 (m), 406 (m); elemental analysis calc. $\left(\mathrm{C}_{30} \mathrm{H}_{34} \mathrm{FeN}_{4}, 506.47 \mathrm{~g} / \mathrm{mol}\right) \mathrm{C} 71.14 \mathrm{H} 6.77 \mathrm{~N} 11.03$, exp. C $70.52 \mathrm{H} 6.64 \mathrm{~N}$ 10.84. Single crystals, suitable for X-ray diffraction analysis, were obtained from a saturated pentane solution placed at $-38{ }^{\circ} \mathrm{C} . \mu_{\mathrm{eff}}=4.80 \mu_{\mathrm{B}}$ (Evans, $\mathrm{C}_{6} \mathrm{D}_{6}+1 \% \mathrm{TMS}, 400.1 \mathrm{MHz}$, r.t.).

$\mathrm{Fe}\left(\mathrm{N} 2_{\text {Dipp }}\right)_{2}, 2$. To a solution of 2-[(diisopropylphenylamino)methyl]pyridine (HN2 ${ }_{\text {Dipp }}, 268$ mg, 1.0 mmol, 1 equiv. $)$ in $\mathrm{Et}_{2} \mathrm{O}(5 \mathrm{~mL})$ was added $\mathrm{Fe}\left(\mathrm{N}\left(\mathrm{SiMe}_{3}\right)_{2}\right)_{2}(188 \mathrm{mg}, 0.5 \mathrm{mmol}, 0.5$ equiv.) dissolved in $2 \mathrm{~mL}$ of pentane at room temperature, resulting in an immediate color change to red. After $1 \mathrm{~h}$ of stirring at the same temperature, the solution was filtered, the solvent evaporated under reduced pressure and the red residue washed with $5 \mathrm{~mL}$ of pentane 
to yield $225 \mathrm{mg}$ of $2(0.25 \mathrm{mmol}, 50 \%)$. ${ }^{1} \mathrm{H}$ NMR (400.1 MHz, $\left.\mathrm{C}_{6} \mathrm{D}_{6}, 298 \mathrm{~K}\right) \delta=125,79.8$, 45.01, 38.75, 37.85, 11.80, -32.1, -34.94; IR (ATR, $\left.\mathrm{cm}^{-1}\right)=2953(\mathrm{~m}), 2859(\mathrm{w}), 2749(\mathrm{w})$, $1477(w), 1456(w), 1429(\mathrm{~s}), 1357$ (w), 1343 (w), 1307 (m), 1247 (s), $1209(\mathrm{w}), 1200(\mathrm{w})$, 1151 (m), 1110 (m), 1073 (s), 1045 (s), 1012 (w), 904 (m), 799 (m), 752 (vs), 719 (m), 620 (w), 586 (w), 554 (w), 416 (vs); elemental analysis calc. $\left(\mathrm{C}_{36} \mathrm{H}_{46} \mathrm{FeN}_{4}, 590.64 \mathrm{~g} / \mathrm{mol}\right) \mathrm{C} 73.21$ H 7.85 N 9.49, exp. C 72.73 H 8.22 N 9.40. Single crystals, suitable for X-ray diffraction analysis, were obtained by slow diffusion of pentane into a saturated $\mathrm{Et}_{2} \mathrm{O}$ solution at $-38^{\circ} \mathrm{C}$. $\mu_{\text {eff }}=4.85 \mu_{\mathrm{B}}\left(\right.$ Evans, $\mathrm{C}_{6} \mathrm{D}_{6}+1 \% \mathrm{TMS}, 400.1 \mathrm{MHz}$, r.t. $)$.

$\mathrm{Fe}\left(\mathrm{HN} 3_{\text {Dipp }}\right)_{2} \cdot \mathrm{C}_{5} \mathrm{H}_{12}, \quad 3 . \quad 2,6$-bis $[($ mesitylamino $)$ methyl $]$ pyridine $\left(\mathrm{H}_{2} \mathrm{~N} 3_{\text {Dipp }}, 305 \mathrm{mg}, 0.67\right.$ mmol, 1 equiv.) was dissolved in $5 \mathrm{~mL}$ of $\mathrm{Et}_{2} \mathrm{O}$ and filtered. By addition of a solution of $\mathrm{Fe}\left(\mathrm{N}\left(\mathrm{SiMe}_{3}\right)_{2}\right)_{2}(125 \mathrm{mg}, 0.34 \mathrm{mmol}, 0.5$ equiv. $)$ in $2 \mathrm{~mL}$ of $\mathrm{Et}_{2} \mathrm{O}$ an immediate color change to reddish violet was observed. After stirring for $2 \mathrm{~h}$ at room temperature, the solution was filtered and all volatiles were removed in vacuo. Washing the residue with $3 \mathrm{~mL}$ of cold $\mathrm{Et}_{2} \mathrm{O}$ $\left(-38^{\circ} \mathrm{C}\right)$ and $3 \mathrm{~mL}$ of cold pentane $\left(-38^{\circ} \mathrm{C}\right)$ with subsequent drying in vacuo yields $200 \mathrm{mg}$ of $\mathrm{Fe}\left(\mathrm{HN} 3_{\text {Dipp }}\right)_{2}(0.20 \mathrm{mmol}, 61 \%) .{ }^{1} \mathrm{H}$ NMR $\left(400.1 \mathrm{MHz}, \mathrm{C}_{6} \mathrm{D}_{6}, 298 \mathrm{~K}\right) \delta=72.11,44.93,44.25$, $40.43,34.95,17.35,7.58,-3.71,-13.56,-19.53,-31.56,-34.94 ;$ IR $\left(\right.$ ATR, $\left.\mathrm{cm}^{-1}\right)=3052(\mathrm{vw})$ 2953 (s), 2927 (w), 2862 (m), 2724 (vw), 1599 (w), 1565 (w), 1459 (vs), 1427 (vs), 1382 (m), 1358 (m), 1310 (s), 1253 (vs), 1194 (m), 1156 (w), 1112 (m), 1076 (m), 931 (w), 888 (w), 873 (w), 800 (s), 770 (vs), 760 (vs), 713 (vs), 548 (w), 438 (w), 414 (vs); elemental analysis calc. $\left(\mathrm{C}_{67} \mathrm{H}_{96} \mathrm{FeN}_{6}, 1041.35 \mathrm{~g} / \mathrm{mol}\right) \mathrm{C} 77.27 \mathrm{H} 9.29 \mathrm{~N} 8.07$, exp. C $76.32 \mathrm{H} \mathrm{9.56} \mathrm{N} \mathrm{8.23.} \mu_{\mathrm{eff}}=$ $4.98 \mu_{\mathrm{B}}$ (Evans, $\mathrm{C}_{6} \mathrm{D}_{6}+1 \% \mathrm{TMS}, 400.1 \mathrm{MHz}$, r.t.). Single crystals, suitable for X-ray diffraction analysis, were obtained from slow evaporation of a saturated pentane solution at r.t. $\mu_{\text {eff }}=4.80 \mu_{\mathrm{B}}\left(\right.$ Evans, $\mathrm{C}_{6} \mathrm{D}_{6}+1 \% \mathrm{TMS}, 400.1 \mathrm{MHz}$, r.t.). 
Crystallography. Data for $\mathbf{1}$ and $\mathbf{3}$ were collected at low temperature (180 K and $100 \mathrm{~K}$ respectively) on a Gemini Agilent diffractometer using a graphite-monochromated Mo-K $\alpha$ radiation and equipped with an Oxford Instrument Cooler Device. Data for $\mathbf{2}$ were collected at $100 \mathrm{~K}$ on a Bruker Kappa Apex II diffractometer using a graphite-monochromated Mo-K $\alpha$ radiation $(\lambda=0.71073 \AA)$ and equipped with an Oxford Cryosystems Cryostream Cooler Device. The structures have been solved using SUPERFLIP ${ }^{9}$ or SHELXS- $97^{10}$ and refined by means of least-squares procedures using the software package CRYSTALS. ${ }^{11}$ The atomic scattering factors were taken from International Tables for X-Ray Crystallography. ${ }^{12}$ All nonhydrogen atoms were refined anisotropically. All hydrogens atoms were refined by using a riding model. ${ }^{13}$ Absorption corrections were introduced by using the MULTISCAN program. ${ }^{14}$ Drawings of molecules were performed with the programs DIAMOND and POVRay. $\mathrm{H}$ atoms are omitted for clarity. Full crystallographic data and structure refinement for compounds 1-3 are gathered in Table SI2.

Magnetic measurements. The samples for magnetic measurements were prepared in a glovebox under argon atmosphere and were introduced as polycrystalline powders into quartz tubes with solid eicosane. The tube was then gently warmed to melt the eicosane, ensuring a good mixing to avoid torqueing of the crystallites and provide good thermal contact between the samples and the cryogenic bath. The quartz tubes were closed with a plastic cork which was immediately melted after exiting the tube from the glovebox. Magnetic susceptibility measurements were carried out with a Quantum Design MPMS-5S SQUID susceptometer. The absence of ferromagnetic impurities was checked by measurement of $M v s . H$ at $100 \mathrm{~K}$. dc measurements were conducted from 300 to $2 \mathrm{~K}$ at $1 \mathrm{kOe}$ and the data were corrected for the diamagnetic contribution of the sample holder, grease and sample by using Pascal's tables. ${ }^{15}$ The field dependences of the magnetization were measured at several temperatures between 2 and $10 \mathrm{~K}$ with dc magnetic field up to $5 \mathrm{~T}$. ac susceptibility experiments were 
performed at various frequencies ranging from 1 to $1500 \mathrm{~Hz}$ with an ac field amplitude of 3 Oe.

Computations. The method proposed in $2009^{16}$ to extract the $D$ and $E$ parameters from the computed spectrum and wavefunctions of low energy and the effective Hamiltonian theory ${ }^{17}$ has been adapted to an $S=2$ pseudo-spin. The analytical derivation of the model Hamiltonian $\widehat{H}_{\text {mod }}=\hat{\vec{S}} \cdot \overline{\bar{D}} \cdot \hat{\vec{S}}$ in the $\{|2,-2\rangle,|2,-1\rangle,|2,0\rangle,|2,+1\rangle,|2,+2\rangle\}$ basis set of the five $\mathrm{M}_{\mathrm{s}}$ components of the quintet ground state gives the representative matrix shown Table SI3.

All matrix elements can be numerically determined. In a first step, the Complete Active Space Self Consistent Field (CASSCF) method has been used to determine the wave functions and energies of the lowest quintet and triplet states. Then a correlated electronic spectrum has been computed adding a second-order perturbative evaluation of electron dynamic correlation corrections to the CASSCF energies. Finally the various states have been coupled through the spin-orbit interaction.

The second step consists in extracting the matrix elements from the effective Hamiltonian theory. For this purpose, a numerical effective Hamiltonian $\left(\mathrm{H}_{\mathrm{eff}}\right)$ is built from the wave functions and energies of the five components of the quintet ground state. This method is extensively described in one of our publication ${ }^{16}$ and is only shortly reviewed here. A model space based on the five $\{|2,-2\rangle,|2,-1\rangle,|2,0\rangle,|2,+1\rangle,|2,+2\rangle\}$ configurations is defined. Then, the $\mathrm{H}_{\text {eff }}$ matrix is determined so that its eigenvalues coincide exactly with those of the five $M_{s}$ components of the quintet ground state and its eigenvectors are the projections of the quintet component wave functions onto the model space. Comparison between the numerical values of $\mathrm{H}_{\text {eff }}$ and the expression of the ZFS tensor in the same basis provides a direct evaluation of $D_{\mathrm{xx}}, D_{\mathrm{yy}}, D_{\mathrm{yy}}, D_{\mathrm{xy}}, D_{\mathrm{xy}}$, and $D_{\mathrm{yz}}$. Finally, the diagonalization of the $\overline{\bar{D}}$ tensor gives the $D$ and $E$ values and allows the determination of the magnetic axes. 
Calculations have been performed using both Molcas $8.0^{18}$ and ORCA $3.0 .3^{19}$ packages. Electronic energies of the lowest states have been calculated at the CAS-PT2 ${ }^{20}$ and NEVPT2 21 levels of correlation while the spin-orbit interactions have been introduced via the Spin-Orbit State Interaction (SO-SI) method ${ }^{22}$. X-Ray geometrical structures of complexes $\mathbf{1}, \mathbf{2}$ and $\mathbf{3}$ were used in the calculations. The $\operatorname{CAS}(6,5)$ contains 6 electrons in 5 active $\mathrm{d}$ orbitals essentially located on the iron ion while in $\operatorname{CAS}(6 / 10)$ an additional set of diffuse $\mathrm{d}$ orbitals has also been included in the active space, as such a procedure has shown to provide better results ${ }^{16}$

In Molcas calculations, $\mathrm{ANO}-\mathrm{RCC}^{23}$ atomic basis sets are used: $6 \mathrm{~s} 5 \mathrm{p} 3 \mathrm{~d} 2 \mathrm{f}$ for Fe, $3 \mathrm{~s} 2 \mathrm{p}$ for $\mathrm{C}$ and $\mathrm{N}$ and $1 \mathrm{~s}$ for $\mathrm{H}$. Orca calculations were performed using cc-(p)VDZ Dunning ${ }^{24}$ atomic basis sets: $6 \mathrm{~s} 5 \mathrm{p} 3 \mathrm{~d} 1 \mathrm{f}$ for $\mathrm{Fe}, 3 \mathrm{~s} 2 \mathrm{p} 1 \mathrm{~d}$ for $\mathrm{C}$ and $\mathrm{N}$ and $2 \mathrm{~s}$ for $\mathrm{H}$.

The impact of the computational parameters (atomic basis set quality, size of the active space, methods to calculate dynamic correlation corrections and the number of states included in the SO-SI matrix) on $D$ and $E$ has been studied for complex $\mathbf{1}$ and is discussed in Supplementary Information.

\section{RESULTS AND DISCUSSION.}

\section{Synthesis.}

$\mathrm{Fe}\left(\mathrm{N}\left(\mathrm{SiMe}_{3}\right)_{2}\right)_{2}$ is a reactive complex, ${ }^{8 \mathrm{a} .25}$ notably toward compounds featuring amine moiety. The coordination of such compounds generate amido ligand and release the volatile bis(silyl)amine $\left.\mathrm{HN}(\mathrm{SiMe})_{3}\right)_{2} \cdot{ }^{5 b-d .26}$ Following a similar synthetic strategy, $\mathrm{Fe}\left(\mathrm{N}\left(\mathrm{SiMe}_{3}\right)_{2}\right)_{2}$ was reacted with 2 equivalents of the respective amido-pyridine ligand ( $\mathrm{HN} 2_{\text {mes }}$ for $\mathbf{1}$; $\mathrm{HN} 2_{\text {Dipp }}$ for 2; $\mathrm{H}_{2} \mathrm{~N} 3_{\text {Dipp }}$ for 3, see Scheme 1), resulting in a rapid color change to red. Workup afforded the respective compounds $\mathbf{1 - 3}$ in good yields (50-76\%). All compounds are highly oxygen 
sensitive, and decompose within weeks in the glovebox at room temperature. The compounds were characterized by X-ray diffraction, ${ }^{1} \mathrm{H}$ NMR, IR spectroscopy, elemental analysis and cyclic voltammetry (see Supporting Information). Their magnetic features were determined in solution by Evans method as well as in solid state by SQUID measurements.

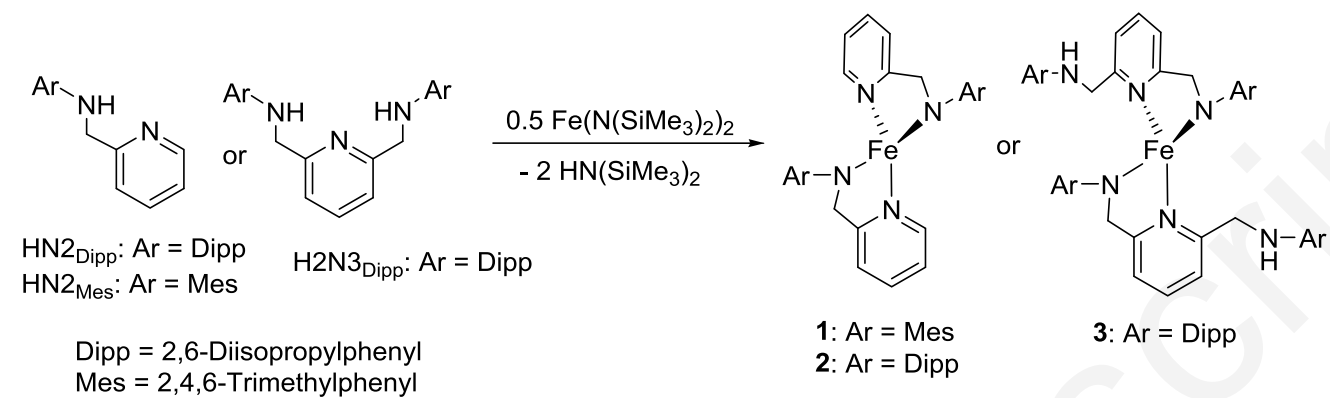

Scheme 1. Syntheses of compounds 1-3.

\section{Solution characterization.}

${ }^{1} \mathrm{H}$ NMR spectroscopy for $\mathbf{1 - 3}$ shows a characteristic pattern between +130 and $-40 \mathrm{ppm}$ (Figures SI2, SI5 and SI8). By comparison between 2 and 3, the low field shifted signals correspond to the protons of the pyridyl and amide bound aryl part. Magnetic moments were

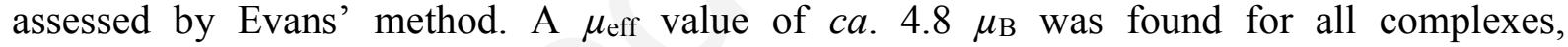
confirming a high-spin $(S=2)$ electronic configuration. The $\mathrm{Fe}^{\mathrm{II}} / \mathrm{Fe}^{\mathrm{III}}$ redox potentials were significantly different. The cyclic voltammetry of $\mathbf{1 - 3}$ in THF (scan rate of 100-200 mV/s) indeed spans over a range of $0.4 \mathrm{~V}\left(\mathbf{1}:-0.94 \mathrm{~V}, 2:-0.87 \mathrm{~V}\right.$ and 3: $-0.53, v s . \mathrm{Fc} / \mathrm{Fc}^{+}$, Figures SI4, SI7 and SI10).

\section{Solid state characterization.}

Single-crystals suitable for X-Ray diffraction analysis were obtained for the three compounds. Complexes 1-3 crystallized in the monoclinic $P 2{ }_{1}, C 2 / c$ and triclinic $P-1$ space groups, respectively. Their crystal structures are shown in Figure 1. 


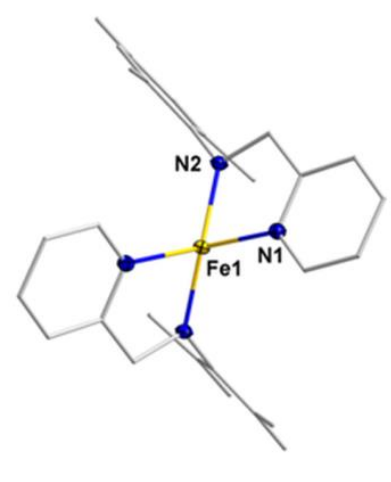

1

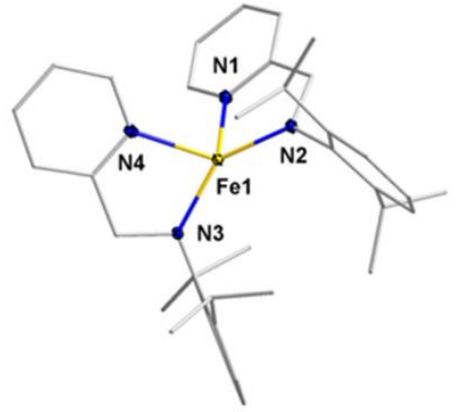

2

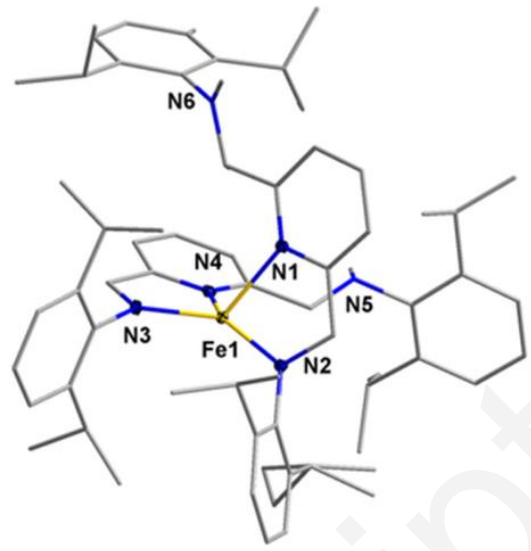

3

Figure 1. Molecular crystal structure of 1-3 (ellipsoids of the $\mathrm{N}$ and $\mathrm{Fe}$ atoms at $30 \%$ probability). $\mathrm{H}$ atoms (except the amine $\mathrm{H}$ atoms and a pentane molecule in case of $\mathbf{3}$ ) are omitted for clarity.

In each complex, the $\mathrm{Fe}^{\mathrm{II}}$ center is tetracoordinated, surrounded by two amido-pyridine ligands, coordinated in a bidentate fashion. The bond distances are similar in the three complexes: for example, the Fe-N distances vary by only 2 and $0.5 \%$ in the $\mathrm{Fe}-\mathrm{N}_{\mathrm{Py}}$ and $\mathrm{Fe}-$ $\mathrm{N}_{\mathrm{am}}$ fragments, respectively (see Table 2). In addition, these parameters are in the same range as the one observed by Westerhausen et al. in analogous high-spin tetrahedral $\mathrm{Fe}^{\mathrm{II}}$ complexes. $^{5 \mathrm{~b}}$ In $\mathbf{1}$, the $\mathrm{Fe}^{\mathrm{II}}$ center resides along a 2-fold screw axis leading to two crystallographically equivalent ligands. In the case of $\mathbf{3}$, the additional amine groups remain pendants. Yet, some N-Fe-N angles and the dihedral angle defined by the two NFeN planes of each ligand varies significantly: $89.8^{\circ}$ for $\mathbf{1}, 69.0^{\circ}$ for $\mathbf{2}$ and $75.3^{\circ}$ for $\mathbf{3}$ (see Table 2 )..$^{5}$ Finally, the iron centers are well separated within the crystal lattice, with $\mathrm{Fe} \cdots \mathrm{Fe}$ distances of at least $8.3 \AA$ (Table 2 ). The 3 -D crystal packing is promoted by short contact interactions between aromatic rings for $\mathbf{1}$ (Figure SI11) and neighboring isopropyl groups for $\mathbf{2}$ and $\mathbf{3}$ (Figures SI12 and SI13). 
Table 2. Selected structural parameters of compounds 1-3 in the solid state.

\begin{tabular}{|c|c|c|c|}
\hline Compound & 1 & 2 & 3 \\
\hline \multicolumn{4}{|l|}{ Distances /Å } \\
\hline Fe1-N1 & $2.1238(9)$ & $2.1257(12)$ & $2.1690(16)$ \\
\hline Fe1-N2 & $1.9397(8)$ & $1.9313(9)$ & $1.9304(19)$ \\
\hline Fe1-N3(N2') & $1.9397(8)$ & $1.9307(10)$ & $1.935(2)$ \\
\hline Fe1-N4(N1') & $2.1238(9)$ & $2.1522(11)$ & $2.1623(12)$ \\
\hline $\mathrm{Fe} \cdot \mathrm{Fe}$ & $8.3442(4)$ & $9.5481(4)$ & $8.8056(9)$ \\
\hline \multicolumn{4}{|l|}{ Angles $/{ }^{\circ}$} \\
\hline N1-Fe1-N2 & $81.28(4)$ & $81.13(4)$ & $81.76(8)$ \\
\hline N1-Fe1-N3 & $117.72(4)$ & $126.54(4)$ & $121.44(8)$ \\
\hline N1-Fe1-N4 & $104.70(4)$ & $92.11(4)$ & $99.11(7)$ \\
\hline $\mathrm{N} 2-\mathrm{Fe} 1-\mathrm{N} 3$ & $150.25(3)$ & $141.70(5)$ & $136.65(8)$ \\
\hline N2-Fe1-N4 & $117.72(4)$ & $129.42(5)$ & $134.19(6)$ \\
\hline $\mathrm{N} 3-\mathrm{Fe} 1-\mathrm{N} 4$ & $81.28(4)$ & $80.39(5)$ & $81.68(7)$ \\
\hline \multicolumn{4}{|l|}{$\begin{array}{l}\text { Dihedral } \\
\text { angle }{ }^{\circ}\end{array}$} \\
\hline $\begin{array}{l}\text { N1-Fe-N2/N3- } \\
\text { Fe-N4 }\end{array}$ & 89.8 & 69.0 & 75.3 \\
\hline
\end{tabular}

The description of the overall geometry is not straightforward since the metal center lies between tetrahedron and seesaw coordination arrangement. We thus sought for additional information by carrying out Continuous Shape Measurement ${ }^{27}(\mathrm{CShM})$ calculations. CShM values provide a quantitative measurement about the deviation of a given coordination sphere from the ideal geometry for which shape values equal to zero. Table SI1 gathers the results of the calculations performed considering all the possible geometries for a four coordinate complex. Every complex exhibits a polyhedral shape deviating markedly from an ideal geometry and best described as distorted tetrahedral or see-saw coordination arrangement. Figure SIl provides further visual information about their relative distortion. These complexes are located outside the distortion path expected between tetrahedral and see-saw due to bond length distortions. A minimal distortion path analysis was also carried out with SHAPE for 1-3 along the distortion pathway from tetrahedral (T-4) to see-saw (SS-4). The results are summarized in Table 3 . The deviation path parameter equals to $0 \%$ for ideal $T_{\mathrm{d}}$ 
geometry and $100 \%$ for see-saw one. The values range between $53.6 \%$ for $\mathbf{1}$ to $80.2 \%$ for 2 with an intermediate value of $65.1 \%$ for 3 .

Table 3. Minimal distortion path (DevPath) analysis using SHAPE for compounds 1-3 from T-4 (0 \%) to SS-4 (100\%).

\begin{tabular}{llll}
\hline Compound & $\mathrm{T}^{\mathrm{a}} 4^{\mathrm{a}}$ & $\mathrm{SS}^{\mathrm{b}}{ }^{\mathrm{b}}$ & DevPath \\
\hline$\left[\mathrm{Fe}\left(\mathrm{N} 2_{\text {mes }}\right)_{2}\right](\mathbf{1})$ & 6.206 & 5.514 & 53.6 \\
{$\left[\mathrm{Fe}\left(\mathrm{N} 2_{\text {Dipp }}\right)_{2}\right](\mathbf{2})$} & 7.778 & 8.222 & 80.2 \\
{$\left[\mathrm{Fe}\left(\mathrm{HN} 3_{\text {Dipp }}\right)_{2}\right] \cdot \mathrm{C}_{5} \mathrm{H}_{12}(\mathbf{3})$} & 6.598 & 6.892 & 65.1 \\
\hline${ }^{\mathrm{a}} \mathrm{T}-4$ stands for $\mathrm{T}_{\mathrm{d}}$ (Tetrahedron) \\
\\
${ }^{\mathrm{b}} \mathrm{SS}-4$ stands for $\mathrm{C}_{2 \mathrm{v}}$ (Seesaw)
\end{tabular}

Magnetic properties.

The temperature dependence of the molar magnetic susceptibility ( $\chi_{M}$ defined as $M / H$ per mole of $\mathrm{Fe}^{\mathrm{II}}$ complex) for 1-3 are shown as $\chi_{M T} v_{s} . T$ plots in Figure 2. The room temperature values of $3.10,3.16$ and $3.21 \mathrm{~cm}^{3} \mathrm{~K} \mathrm{~mol}^{-1}\left(5.03,4.97\right.$, and $\left.5.05 \mu_{\mathrm{B}} \mathrm{mol}^{-1}\right)$ are consistent with the values determined by the Evans method (Table 4). Upon cooling, the $\chi_{M} T$ product of 1-3 remains constant until $c a$. $50 \mathrm{~K}$ below which a quick drop can be observed. This susceptibility decrease can be attributed to the ZFS effect (magnetic anisotropy) because the magnetic centers are quite well separated in the solid (see structure description above). 


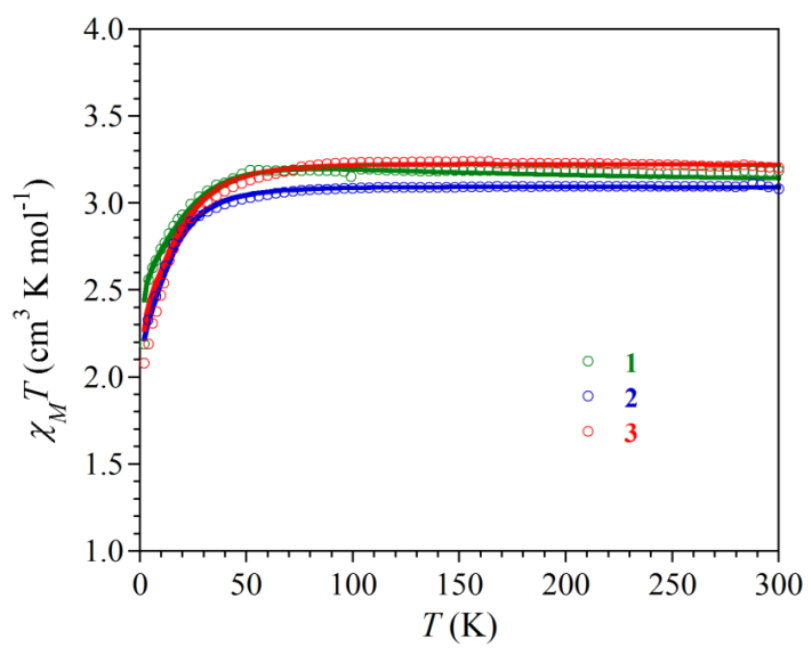

Figure 2. Temperature dependence of $\chi_{M T}$ for $\mathbf{1 - 3}$ with the best fits in solid lines (see parameters in the text).

Table 4. Magnetic moments of 1-3 in solid state and solution.

\begin{tabular}{llll}
\hline Compound & $\begin{array}{l}\mu_{\text {eff }}\left(\mu_{\mathrm{B}} \mathrm{mol}^{-1}\right) \\
\text { solid state }\end{array}$ & $\begin{array}{l}\mu_{\text {eff }}\left(\mu_{\mathrm{B}} \mathrm{mol}^{-1}\right) \\
\text { solution }\end{array}$ & $M$ at 2 K and $5 \mathrm{~T}\left(\mu_{\mathrm{B}}\right)$ \\
\hline$\left[\mathrm{Fe}\left(\mathrm{N} 2_{\text {mes }}\right)_{2}\right](\mathbf{1})$ & 5.03 & 4.80 & 2.70 \\
{$\left[\mathrm{Fe}\left(\mathrm{N} 2_{\text {Dipp }}\right)_{2}\right](\mathbf{2})$} & 4.97 & 4.85 & 2.23 \\
{$\left[\mathrm{Fe}\left(\mathrm{HN} 3_{\text {Dipp }}\right)_{2}\right] \cdot \mathrm{C}_{5} \mathrm{H}_{12}(\mathbf{3})$} & 5.05 & 4.80 & 2.38 \\
\hline
\end{tabular}

In transition-metal complexes, the effect of ZFS on the magnetic properties is usually observed at low temperatures. Thus, the most sensitive and accurate evaluation of the magnetic anisotropy of polycrystalline samples from SQUID data relies on the field and temperature-dependent measurements of their magnetization. The field-dependence of the magnetization $(M)$ measured for 1-3 are plotted in Figures 3 and SI13 under the form of $M v s$. $H$. The magnetization obtained at $2 \mathrm{~K}$ under a field of $5 \mathrm{~T}$ are $2.70(\mathbf{1}), 2.23(\mathbf{2})$ and $2.38(\mathbf{3})$ $\mu_{\mathrm{B}}$, values lower than expected for a spin-only $S=2$ system (i.e. $4 \mu_{\mathrm{B}}$ ). Interestingly, the magnetization curves are not matching on a single master curve (Figure SI15), a characteristic indicative for significant magnetic anisotropy in these complexes. This anisotropy was estimated considering the ZFS axial and rhombic magnetic anisotropy parameters $D$ and $E$ by 
concomitant fits of $M v s . H$ and $\chi_{M} T v s . T$ curves with the program $\mathrm{PHI}^{28}$ yielding negative $D$ values of respectively $-12.3(1) \mathrm{cm}^{-1}(1),-16.9(7) \mathrm{cm}^{-1}(2)$, and $-16.5(5) \mathrm{cm}^{-1}(3)$. In the case of complexes $\mathbf{1}$ and $\mathbf{2}$, fits of analogous quality could be reached with or without taking into account the $E$ parameter. For complex 3, it was necessary to add the contribution of the rhombic anisotropy $E$ to reach good reproduction of the data. However, the experimental errors on this parameter is high keeping in mind that the intermolecular interactions $\left(z J^{\prime}\right)$ were neglected to avoid overparametrization. The set of parameters determined from the best fits shown in Figures 3 and SI13 are gathered in Tables 5 and 6. These parameters were systematically validated by at least two investigations on different batches. Fitting the data with positive $D$ values were also attempted but this only led to unsatisfactory $E / D$ ratios (higher than 0.33 ). The effect of the geometry distortion on $D$ for these complexes will be discussed below.

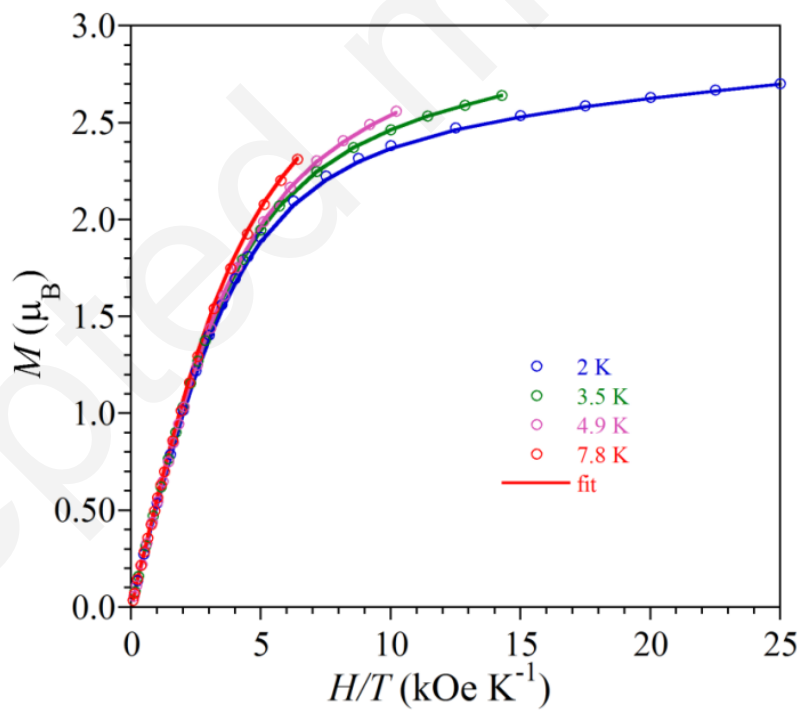

Figure 3. Field dependence of the magnetization $(M)$ for $\left[\mathrm{Fe}\left(\mathrm{N} 2{ }_{\mathrm{mes}}\right)_{2}\right](\mathbf{1})$ with the best fits in solid lines (see parameters in the text).

The easy-axis (Ising-type) magnetic anisotropy exhibited by 1-3 prompted us to examine the possibility for blocking of the magnetization. Therefore alternating current (ac) magnetic susceptibility measurements have been carried out to detect any slow relaxation of the 
magnetization. No out-of-phase susceptibility $\left(\chi_{\mathrm{M}}\right.$ ') signals were detected in zero dc field, but upon application of an external field, a response was observed with visible maxima in $\chi_{\mathrm{M}}$ ' curves above $2 \mathrm{~K}$ for $\mathbf{1}$ and $\mathbf{2}$ (Figure SI17). The relaxation times $(\tau)$ were determined at each temperature fitting the $\chi_{\mathrm{M}} "=\mathrm{f}(v)$ curves with a generalized Debye model ${ }^{29}$ For $\mathbf{2}, \chi_{\mathrm{M}}{ }^{\prime}$ $=\mathrm{f}(v)$ is only slightly frequency-dependent (Figure SI19) revealing an almost temperature independent relaxation regime likely stemming from multiple spin-lattice vibrational relaxation mechanisms with a main contribution from quantum tunneling of the magnetization (QTM).

For 1, a linear dependence of the relaxation time was found above $3 \mathrm{~K}$ (Figure 4a), suggesting a thermally activated regime characteristic of a SMM behavior. For lower temperatures, the $\tau=\mathrm{f}(1 / T)$ curve deviates from linearity highlighting contributions from additional relaxation modes shortcutting the thermal relaxation pathway. In mononuclear complexes, QTM, Raman and direct spin-phonon processes are often playing an important role in the magnetization dynamics when a dc field is applied. ${ }^{30}$ The coexistence of multirelaxation processes is also suggested by the relatively large distribution of relaxation times obtained from the analysis of the Cole-Cole plots ( $\alpha$ parameter in Table SI4 corresponding to the fits shown Figure SI20). ${ }^{31}$ Quantum tunneling contributions were neglected to avoid overparametrization as QTM is usually minimized under external magnetic field. This is also supported by the temperature dependence of the out-of-phase susceptibility $\chi$ '” maximum even at the lowest temperatures. Direct spin-lattice process is known to operate in the low temperature regime under applied $\mathrm{dc}$ field $\mathrm{d}^{32}$ and to be field dependent (equation 1). As the position of the ac maximum of $\mathbf{1}$ is field dependent (Figure SI17a) and Ising-type magnetic anisotropy promotes Orbach relaxation, the temperature dependence of $\tau$ was fitted taking into account direct and Orbach relaxation mechanisms (equation 1). 


$$
\tau^{-1}=A H^{2} T+\tau_{0}^{-1} \exp \left(\frac{-U_{e f f}}{k_{B} T}\right)(1)
$$

A good fit was obtained from this model with $A=2.1810^{-4} \mathrm{~s}^{-1} \mathrm{Oe}^{-2} \mathrm{~K}^{-1}$ ( $A$ is a coefficient and $H$ is the external dc field), $\tau_{0}=3.310^{-9} \mathrm{~s}$ and $U_{\text {eff }}=26.7 \mathrm{~cm}^{-1}$ (Figure $4 \mathrm{~b}$ ). Raman and Orbach mechanisms were also considered but this other model was excluded because the Raman values are not coherent for integer spin ground state (see Supporting Information, Figure SI21). ${ }^{30 \mathrm{~d} .33}$ The effective energy barrier for $\mathbf{1}$ is of the same order of magnitude and compares with the anticipated Orbach barrier $3 *|D|=37 \mathrm{~cm}^{-1}$.
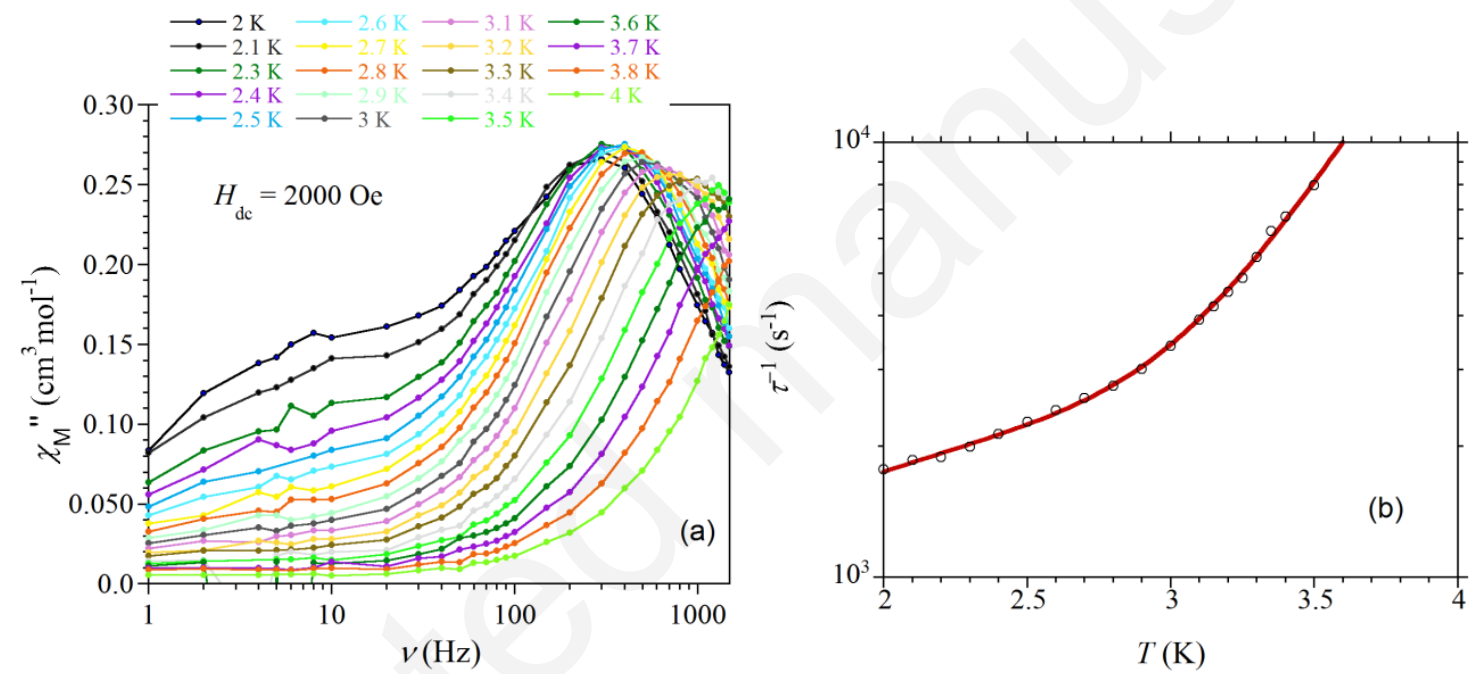

Figure 4. (a) Frequency dependence of the out-of-phase ac magnetic susceptibility ( $\chi_{\mathrm{M}}$ ") of $\left[\mathrm{Fe}\left(\mathrm{N} 2 \mathrm{mes}_{2}\right)_{2}\right](\mathbf{1})$ as a function of the temperature recorded under an applied dc field of 2000 Oe (the solid lines are guides for the eyes). (b) $\tau^{-1} v s . T$ plot for 1 with the least-square fit of the data materialized by the solid line using equation 1 (see parameters in the text).

Slow relaxation of the magnetization is also present in $\mathbf{3}$ but at lower temperatures (Figure SI17c), preventing further studies to estimate the energy barrier for spin reversal. It can be noticed that the magnetization blocking characteristics found for 1-3 do not parallel the magnetic anisotropy exhibited by the complexes. Indeed, compound $\mathbf{1}$ with smallest magnetic 
anisotropy is the only compound for which an energy barrier for spin reversal could be evaluated. Such a behavior is not unusual and was observed for the $\left[\mathrm{Fe}\left(\operatorname{tpa}^{\mathrm{X}}\right)\right]^{-} \operatorname{complexes}^{2}$ or in a family of four-coordinated $\mathrm{Co}^{\mathrm{II}}$ complexes (Table 5). ${ }^{34}$ It must be kept in mind that different mechanisms regulate the relaxation of the magnetization and their relative contributions are strongly dependent of the lattice vibrations. ${ }^{30 \mathrm{~d} .33 .35}$

Table 5. Magnetic parameters of 1-3 compared with similar four-coordinate $\mathrm{Fe}^{\mathrm{II}}$ complexes.

\begin{tabular}{|c|c|c|c|c|c|c|c|c|}
\hline Compound & $D\left(\mathrm{~cm}^{-1}\right)$ & $\begin{array}{l}E\left(\mathrm{~cm}^{-}\right. \\
1)\end{array}$ & $g$ & $\begin{array}{l}\text { Slow } \\
\text { relaxation }\end{array}$ & $\begin{array}{l}H_{\mathrm{dc}} \\
(\mathrm{Oe})\end{array}$ & $\begin{array}{l}\tau_{0} \\
(\mathrm{~s})\end{array}$ & $\begin{array}{l}U_{\text {eff }} \\
\left(\mathrm{cm}^{-}\right. \\
\left.{ }^{1}\right)\end{array}$ & Ref. \\
\hline$\left[\mathrm{Fe}\left(\mathrm{CF}_{3}-\mathrm{ONO}\right) \mathrm{Cl}\right]$ & 17.4 & 2.44 & $\begin{array}{l}g_{\mathrm{x}}=2.19, \\
g_{\mathrm{y}}=2.18, \\
g_{\mathrm{z}}=2.04\end{array}$ & n.c. & & & & 6 \\
\hline$\left[\mathrm{Fe}\left(\mathrm{N} 2_{\mathrm{mes}}\right)_{2}\right](\mathbf{1})$ & $-12.3(1)$ & $\begin{array}{l} \pm \\
0.01(2)\end{array}$ & $\begin{array}{l}g_{\mathrm{x}, \mathrm{y}}=1.97 \\
g_{\mathrm{z}}=2.12\end{array}$ & Yes & 2000 & $\begin{array}{l}4.2 \\
10^{-7}\end{array}$ & 13.9 & $\begin{array}{l}\text { this } \\
\text { work }\end{array}$ \\
\hline$\left[\mathrm{Fe}\left(\mathrm{N} 2_{\mathrm{Dipp}}\right)_{2}\right](\mathbf{2})$ & $-16.9(7)$ & $\begin{array}{l} \pm \\
0.05(2)\end{array}$ & $\begin{array}{l}g_{\mathrm{x}, \mathrm{y}}=1.99 \\
g_{\mathrm{z}}=2.09\end{array}$ & No & & & & $\begin{array}{l}\text { this } \\
\text { work }\end{array}$ \\
\hline$\left[\mathrm{Fe}\left(\mathrm{HN} 3_{\text {Dipp }}\right)_{2}\right](\mathbf{3})$ & $-16.5(5)$ & $\begin{array}{l} \pm \\
2.13(3)\end{array}$ & $\begin{array}{l}g_{x, y}=2.02, \\
g_{z}=2.17\end{array}$ & Yes & 2000 & - & - & $\begin{array}{l}\text { this } \\
\text { work }\end{array}$ \\
\hline$\left[\mathrm{Fe}(\mathrm{tBuC})_{2}\right]$ & -10.74 & 2.5 & $\begin{array}{l}g_{x, y}=2.1 \\
g_{z}=2.16\end{array}$ & & & & & $4 \mathrm{c}$ \\
\hline $\begin{array}{l}{\left[\mathrm{Fe}\left(\mathrm{N}\left(\mathrm{SiMe}_{3}\right)_{2}\right)_{2}\right.} \\
(\mathrm{depe})]\end{array}$ & +4.1 & - & 2 & No & & & & $4 \mathrm{~d}$ \\
\hline$\left[\mathrm{Fe}\left(\mathrm{C}_{3} \mathrm{~S}_{5}\right)_{2}\right]\left(\mathrm{NBu}_{4}\right)_{2}$ & $+5.61(9)$ & $0.59(2)$ & $\begin{array}{l}g_{\mathrm{x}}=2.00, \\
g_{\mathrm{y}}=2.04, \\
g_{\mathrm{z}}=2.08\end{array}$ & No & & & & $4 \mathrm{a}$ \\
\hline $\begin{array}{l}\mathrm{Na}\left[\left(\operatorname{tpa}^{\mathrm{t}-\mathrm{Bu}}\right) \mathrm{Fe}\right] \cdot \\
\mathrm{THF}\end{array}$ & -48 & 0.4 & 2.3 & Yes & 1500 & $\begin{array}{l}6.7 \\
10^{-} \\
11\end{array}$ & 65 & 2 \\
\hline $\begin{array}{l}\mathrm{K}\left[\left(\mathrm{tpa}^{\mathrm{Mes}}\right) \mathrm{Fe}\right] \cdot 2 \\
\mathrm{DME}\end{array}$ & $-44(4)$ & 6 & 2.2 & Yes & 1500 & $\begin{array}{l}2 \\
10^{-9}\end{array}$ & 42 & 2 \\
\hline $\begin{array}{l}\mathrm{K}\left[\left(\mathrm{tpa}^{\mathrm{Mes}}\right) \mathrm{Fe}\right] \cdot 2 \\
\mathrm{DME}\end{array}$ & -39.6 & -0.4 & 2.21 & Yes & 1500 & $\begin{array}{l}2 \\
10^{-9}\end{array}$ & 42 & 2 \\
\hline $\begin{array}{l}\mathrm{K}\left[\left(\text { tpa }^{\text {Trip }}\right) \mathrm{Fe}\right] \cdot 3 \\
\mathrm{DME}\end{array}$ & $-30(2)$ & 4 & 2.4 & Yes & 1500 & - & - & 2 \\
\hline $\begin{array}{l}\mathrm{Na}\left[\left(\mathrm{tpa}^{\mathrm{Ph}}\right) \mathrm{Fe}\right] \cdot 3 \\
\mathrm{DME}\end{array}$ & $-26(2)$ & 5 & 2.4 & Yes & 1500 & n.c. ${ }^{a}$ & 25 & 2 \\
\hline $\begin{array}{l}\mathrm{K}\left[\left(\mathrm{tpa}^{\mathrm{DFP}}\right) \mathrm{Fe}\right] \cdot 2 \\
\mathrm{DME}\end{array}$ & -6.2 & 0.1 & 2.0 & Yes & 1500 & - & - & 2 \\
\hline
\end{tabular}


Theoretical calculations. Calculations have been performed in order to determine the structural factors which control the magnetic anisotropy in this family of complexes. For a series of pseudo-tetrahedral $\mathrm{Co}^{\mathrm{II}}$ complexes, ab initio calculations revealed the influence of the first and second coordination sphere on the ZFS parameters ${ }^{36}$ depending on the heteroatom coordinated to the metal center. Complexes 1-3 feature similar coordinated amido-pyridine ligands to the $\mathrm{Fe}^{\mathrm{II}}$ ions, hence variation in $D$ can be related to mostly geometrical considerations. The computation methodology described in the experimental section lead to the $D$ and $E$ values reported in Table 6 . They were obtained at CAS(6/10)PT2 level using basis set 1 and considering 5 quintet and 35 triplet states. They are compared to those obtained at the NEVPT2 level for CAS(6/5) for an equivalent atomic basis set. A good agreement of both calculations with experimental values is achieved. The magnetic axes extracted from the $a b$ initio calculations are very similar in the three complexes (see Figure $5)$.

Table 6. Evaluation of $D$ and $E$ from Wave Functions Theory (WFT) calculations compared with the experimental values.

\begin{tabular}{|l|c|c|c|c|c|c|}
\hline & \multicolumn{2}{|c|}{1} & \multicolumn{2}{c|}{2} & \multicolumn{2}{c|}{3} \\
\cline { 2 - 7 } & $D\left(\mathrm{~cm}^{-1}\right)$ & $E\left(\mathrm{~cm}^{-1}\right)$ & $D\left(\mathrm{~cm}^{-1}\right)$ & $E\left(\mathrm{~cm}^{-1}\right)$ & $D\left(\mathrm{~cm}^{-1}\right)$ & $E\left(\mathrm{~cm}^{-1}\right)$ \\
\hline CAS(6/10)PT2 & -10.7 & 0.02 & -16.6 & 1.16 & -15.8 & 0.59 \\
\hline CAS(6/5)NEVPT2 & -13.7 & 0.09 & -19.3 & 1.15 & -18.2 & 0.66 \\
\hline Experimental & $-12.3(1)$ & $\pm 0.01(2)$ & $-16.9(7)$ & $\pm 0.05(2)$ & $-16.5(5)$ & $\pm 2.13(3)$ \\
\hline
\end{tabular}

For the three complexes, the energetic order of the orbitals located on the $\mathrm{Fe}^{\mathrm{II}}$ ions and their occupation in the two first states are reported in Figure 6. The MOs are represented in Figure SI22. The spectra of the lowest quintet states and a perturbative evaluation of the contribution 
of each state on the $D$ value are given in Figure SI23. The main contribution to $D$ is brought by the first excited state that is obtained from the ground state by a single excitation from the $\mathrm{d}_{x 2-y 2}$ to the $\mathrm{d}_{x y}$ orbitals. As these two orbitals are linear combinations of the $\mathrm{d}_{2+}$ and $\mathrm{d}_{2-}$ spherical harmonics, the two states are coupled through the $\hat{l}_{z} \hat{s}_{z}$ part of the spin-orbit operator $\sum_{i} \hat{l}_{z_{i}} \hat{s}_{z_{i}}+\frac{1}{2}\left(\hat{l}_{i}^{+} \hat{s}_{i}^{-}+\hat{l}_{i}^{-} \hat{s}_{i}^{+}\right)$. One can note that the $\mathrm{M}_{\mathrm{s}}= \pm 2$ components of the quintet states are essentially single reference (a single determinant is enough to describe each of the two quintet state components). Hence the coupling is larger for these components than for the others for which several determinants weighted by coefficients lower than 1 are required. As a consequence, the lowering of the $\mathrm{M}_{\mathrm{s}}= \pm 2$ components through the spin-orbit interaction is larger than that of the other components and the contribution to $D$ is therefore negative. It is interesting to note that the energy difference between the ground and first excited state are $2346 \mathrm{~cm}^{-1}, 1445 \mathrm{~cm}^{-1}$, and $1581 \mathrm{~cm}^{-1}$ for complexes $\mathbf{1}, \mathbf{2}$ and $\mathbf{3}$ respectively at the CAS(6/10)PT2 level. As the energetic stabilization due to spin-orbit coupling is inversely proportional to the energy difference between the ground and excited states (at the second order of perturbation), the similar values of $D$ in complexes $\mathbf{2}$ and $\mathbf{3}$ and the smaller value of $|D|$ in complex 1 can be correlated with the energy of the first excited quintet state. One may also conclude that to increase the $|D|$ value one must decrease the energy difference between the $\mathrm{d}_{x 2-y 2}$ and $\mathrm{d}_{x y}$ orbitals. Indeed, this difference is $1840 \mathrm{~cm}^{-1}$ for $\mathbf{1}, 1340 \mathrm{~cm}^{-1}$ for $\mathbf{2}$, and 1450 $\mathrm{cm}^{-1}$ for $\mathbf{3}$, in complete agreement with the evolution of the $D$ value. 

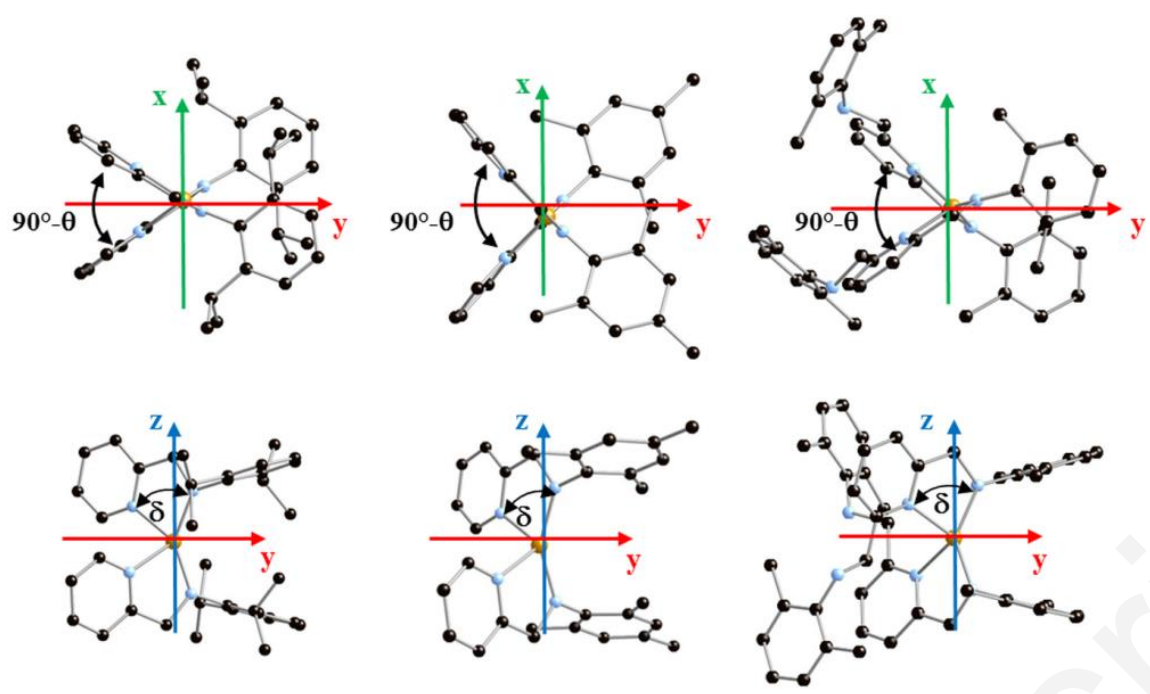

Figure 5. Complexes 1 (left), 2 (center) and $\mathbf{3}$ (right) represented with their magnetic axes projected onto the $(x O y)$ (top) and $(y O z)$ (bottom) planes determined from $a b$ initio calculations. The torsion angle $\theta$ and the N-Fe-N angle $\delta$ (see text) are also represented.

We firstly wanted to understand which distortion from the tetrahedron is responsible for the negative $D$ value. The first deviation from an ideal $T_{d}$ geometry comes from the N-Fe-N angle $\delta$ (see Figure 5) involving two chelating nitrogen atoms, which is close to $80^{\circ}$ in all studied complexes instead of $109^{\circ}$ in a tetrahedron. The second difference comes from the distances between the iron and the nitrogen atoms. In all the complexes, the $\mathrm{Fe}-\mathrm{N}$ bond distances between the amide nitrogen atoms (Fe-N2 and Fe-N3) are shorter than the ones to the pyridine $\mathrm{N}$ atoms (see Table 2). However, the respective Fe-N bond lengths vary only negligibly between the complexes. We secondly wanted to understand how small structural differences in the first coordination sphere between the three complexes affect the $D$ value. The main difference between the complexes comes from the torsion angle $\theta$ which induces a loss of the $C_{2}$ axes present in the tetrahedron. Figure 5 shows a view of the complexes in which the angle of distortion $(\theta)$ is represented. In our definition, an undistorted complex would have an angle between the ligand planes of $90^{\circ}\left(\theta=0^{\circ}\right)$. As the distortion closes this angle which varies from $90^{\circ}$ to $67^{\circ}$ in the complexes, $\theta$ varies from 0 to $23^{\circ}$. The values are $\theta \approx 0^{\circ}, 23^{\circ}$ and $16^{\circ}$ for 1 , 
$\mathbf{2}$ and $\mathbf{3}$ respectively and are a consequence of steric and crystal packing hindrances due to the different chemical groups bound to the pyridine and/or to the phenyl group bound to N2/N3. In order to understand the effect of these distortions (the angular $\delta$, the distances $d$ and the torsion $\theta$ distortions), calculations on three model complexes have been performed: the pyridine group was replaced by $\mathrm{NCH}$ while the $\mathrm{N} 2$ and $\mathrm{N} 3$ atoms were modeled by $\mathrm{NC}^{-}$ anions as the formal charge of the ligand is carried by these $\mathrm{N}$ atoms. In order to check that there is no large bias introduced by the change of chemical groups, we have first calculated the $D$ values in model complexes where the position of the nitrogen atoms is exactly the same as in the real complex and the model ligands are aligned with the metal ion. CAS(6/5)NEVPT2 calculations were then performed. The values of $D\left(-11.7 \mathrm{~cm}^{-1},-14.1 \mathrm{~cm}^{-}\right.$ 1, and $-15.1 \mathrm{~cm}^{-1}$ for models of complexes $\mathbf{1}, \mathbf{2}$ and $\mathbf{3}$ respectively) are in qualitative agreement with the values obtained for the real complexes. Then, starting from the tetrahedron angular, distance, and $\theta$ torsion distortions were applied. The curves of $D$ as function of the three distortions $\delta, \mathrm{d}$ and $\theta$ are represented in Figure SI24. The angular distortion is responsible for the negative $D$ value observed in the three complexes as larger negative $D$ values are found when the bite angle decreases. This result can also be correlated with the energetic order of the orbitals. Indeed, all the orbitals which have XY components are stabilized in comparison to the perfect tetrahedron by the decrease of the angles in the $\mathrm{Z}$ direction. The resulting energetic order of the orbitals is given in Figure 6. In contrast, the deformations (simultaneous elongation of the $\mathrm{Fe}-\mathrm{NCH}$ bonds and contraction of the $\mathrm{Fe}^{-\mathrm{NC}^{-}}$ bonds) have no important effect on the $D$ values. Finally the distortion introduced by $\theta$ is responsible for the differences observed between the three complexes. It induces a significant increase of the absolute value of the negative $D$ parameter. This last result can also be easily rationalized from a ligand field point of view. Indeed, when the system is not distorted the $d_{x 2-}$ 
$y_{2}$ and $\mathrm{d}_{x y}$ orbitals are far apart in energy as the $\mathrm{d}_{x y}$ points towards the ligands while the $\mathrm{d}_{x 2-y 2}$ does not. When the distortion takes place the energy difference between the two orbitals decreases. As a consequence the energy difference between the two quintet states differing by the occupation of these orbitals decreases and the absolute value of $D$ increases. As complex 1 does not show any angular distortion while complexes $\mathbf{2}$ and $\mathbf{3}$ have a non-negligible and similar distortion, one may rationalize why complexes $\mathbf{2}$ and $\mathbf{3}$ have large and similar values of $D$ in comparison to complex $\mathbf{1}$.

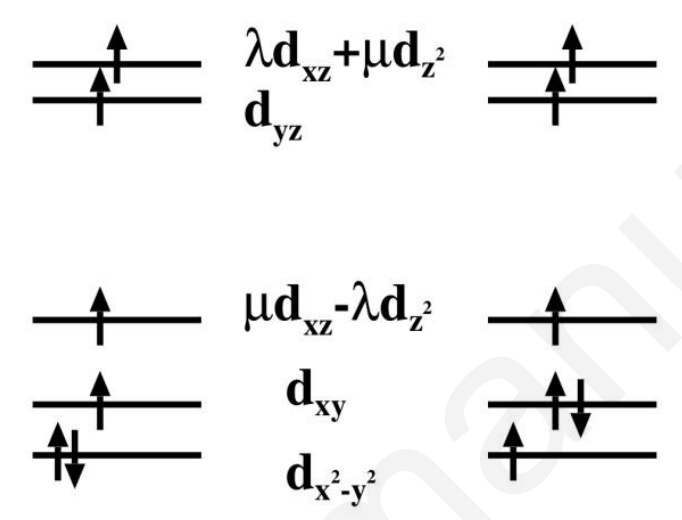

Figure 6. Energetic order and physical content in the magnetic axes frame shown Figure 5 of the magnetic orbitals (essentially $3 \mathrm{~d}$ character) located on the iron ion and their occupation in the ground quintet state (left) and first excited quintet state (right).

Conclusions. This family of four-coordinate bis-(amido-pyridine) $\mathrm{Fe}^{\mathrm{II}}$ complexes provided insights on the distortion effects at the origin of the modulation of the magnetic anisotropy for such tetrahedron-shaped $d^{6}$ centers. The main conclusions are: i) the negative $D$ value arises from the decrease of the N-Fe-N bite angles. This distortion stabilizes the $\mathrm{d}_{x y}$ and $\mathrm{d}_{x 2-y 2}$ orbitals involved in the excitation at the origin of the sign of the magnetic anisotropy of all studied complexes; ii) a further analysis of the structural parameters revealed that the torsion between the planes of the two ligands in the first coordination sphere strongly contributes to the negative $D$ value and is responsible for the difference of $D$ for these complexes. These 
results suggest that larger magnetic anisotropy (i.e. more negative $D$ values) might be anticipated for similar nitrogen-based bidentate ligands with a smaller bite angle and inducing larger torsion between the two chelate planes. The magneto-structural correlation discussed in this work is valid for $\mathrm{Fe}^{\mathrm{II}}$ complexes with intermediate geometry between $T_{\mathrm{d}}$ and $D_{4 \mathrm{~h}}$. A different coordination environment and distortion would modify the orbital splitting and thus the relative contribution of SOC to $D$.

For the reported complexes, $D$ parameters ranging from -17 to $-12 \mathrm{~cm}^{-1}$ have been obtained. Interestingly, field-induced slow magnetic relaxation was detected in all cases despite moderate magnetic anisotropy. A thermally activated relaxation process characterized by an effective energy barrier of $27 \mathrm{~cm}^{-1}$ was observed for complex $\mathbf{1}$.

Associated content. The Supporting Information is available free of charge on the ACS Publication website. X-ray crystallographic files in CIF format for 1-3 (CCDC numbers: 1487407-1487409), additional structural and physico-chemical (electrochemistry, magnetism) characterization data but also supplementary theoretical results.

\section{Author Information.}

Corresponding authors

*E-mail: celine.pichon@1cc-toulouse.fr

*E-mail: nathalie.guihery@irsamc.ups-tlse.fr

*E-mail: sebastien.bontemps@1cc.toulouse.fr

\section{Author Contributions}


The manuscript was written through contributions of all authors. All authors have given approval to the final version of the manuscript.

Acknowledgements. C. P. and J.-P. S. acknowledge CEFIPRA/IFCPAR (Indo-French Center for the Promotion of Advanced Research) for support. J-B. S., C. D., C. G. W., S.S. E. and S. B. thank the ANR (programme blanc "IRONHYC" ANR-12), the DFG (WE 5627/1-1 personal grant for C. G. W.) This work was granted access to the HPC resources of CALMIP supercomputing center under the allocation 2012-P1517, 2011-P1144 and 2015-P0059. 


\section{References.}

1. Sessoli, R.; Gatteschi, D.; Caneschi, A.; Novak, M. A. Magnetic bistability in a metal-ion cluster. Nature 1993, 365, 141-143.

2. Freedman, D. E.; Harman, W. H.; Harris, T. D.; Long, G. J.; Chang, C. J.; Long, J. R. Slow Magnetic Relaxation in a High-Spin Iron(II) Complex. Journal of the American Chemical Society 2010, $132,1224-1225$.

3. (a) Bar, A. K.; Pichon, C.; Sutter, J.-P. Magnetic anisotropy in two- to eight-coordinated transition-metal complexes: Recent developments in molecular magnetism. Coordination Chemistry Reviews 2016, 308, Part 2, 346-380. (b) Gómez-Coca, S.; Aravena, D.; Morales, R.; Ruiz, E. Large magnetic anisotropy in mononuclear metal complexes. Coordination Chemistry Reviews 2015, 289290, 379-392. (c) Frost, J. M.; Harriman, K. L. M.; Murugesu, M. The rise of 3-d single-ion magnets in molecular magnetism: towards materials from molecules? Chemical Science 2016, 7, 2470-2491.

4. (a) Zadrozny, J. M.; Greer, S. M.; Hill, S.; Freedman, D. E. A flexible iron(ii) complex in which zero-field splitting is resistant to structural variation. Chemical Science 2016, 7, 416-423. (b) Lee, W.T.; Jeon, I.-R.; Xu, S.; Dickie, D. A.; Smith, J. M. Low-Coordinate Iron(II) Complexes of a Bulky Bis(carbene)borate Ligand. Organometallics 2014, 33, 5654-5659. (c) Liu, Y.-Z.; Wang, J.; Zhao, Y.; Chen, L.; Chen, X.-T.; Xue, Z.-L. Four-coordinate Co(ii) and Fe(ii) complexes with bis(N-heterocyclic carbene)borate and their magnetic properties. Dalton Transactions 2015, 44, 908-911. (d) Lin, P.-H.; Smythe, N. C.; Gorelsky, S. I.; Maguire, S.; Henson, N. J.; Korobkov, I.; Scott, B. L.; Gordon, J. C.; Baker, R. T.; Murugesu, M. Importance of Out-of-State Spin-Orbit Coupling for Slow Magnetic Relaxation in Mononuclear Fell Complexes. Journal of the American Chemical Society 2011, 133, 15806-15809. (e) Scepaniak, J. J.; Harris, T. D.; Vogel, C. S.; Sutter, J.; Meyer, K.; Smith, J. M. Spin Crossover in a FourCoordinate Iron(II) Complex. Journal of the American Chemical Society 2011, 133, 3824-3827.

5. (a) Lu, C. C.; Bill, E.; Weyhermüller, T.; Bothe, E.; Wieghardt, K. Neutral Bis( $\alpha-$ iminopyridine)metal Complexes of the First-Row Transition lons ( $\mathrm{Cr}, \mathrm{Mn}, \mathrm{Fe}, \mathrm{Co}, \mathrm{Ni}, \mathrm{Zn}$ ) and Their Monocationic Analogues: Mixed Valency Involving a Redox Noninnocent Ligand System. Journal of the American Chemical Society 2008, 130, 3181-3197. (b) Malassa, A.; Herzer, N.; Gorls, H.; Westerhausen, M. Synthesis of heteroleptic iron(ii) 2-pyridylmethylamides and 2pyridylmethylideneamines via the reaction of $[($ thf $) \mathrm{Fe}\{\mathrm{N}(\mathrm{SiMe} 3) 2\} 2 \mathrm{Cl}]$ with (2pyridylmethyl)(trialkylsilyl)amines. Dalton Transactions 2010, 39, 5356-5366. (c) Malassa, A.; Agthe, C.; Görls, H.; Podewitz, M.; Yu, L.; Herrmann, C.; Reiher, M.; Westerhausen, M. Synthesis, Structures, and Magnetic Properties of N-Trialkylsilyl-8-amidoquinoline Complexes of Chromium, Manganese, Iron, and Cobalt as well as of Wheel-Like Hexanuclear Iron(II) and Manganese(II) Bis(8amidoquinoline). European Journal of Inorganic Chemistry 2010, 2010, 1777-1790. (d) Malassa, A.; Agthe, C.; Görls, H.; Friedrich, M.; Westerhausen, M. Deprotonation and dehydrogenation of Di(2pyridylmethyl)amine with $\mathrm{M}[\mathrm{N}(\mathrm{SiMe3}) 2] 2(\mathrm{M}=\mathrm{Mn}, \mathrm{Fe}, \mathrm{Co}, \mathrm{Zn})$ and $\mathrm{Fe}(\mathrm{C} 6 \mathrm{H} 2-2,4,6-\mathrm{Me} 3) 2$. Journal of Organometallic Chemistry 2010, 695, 1641-1650. (e) Velásquez, V. P. L.; Jazzazi, T. M. A.; Malassa, A.; Görls, H.; Gessner, G.; Heinemann, S. H.; Westerhausen, M. Derivatives of Photosensitive CORM-S1 $\mathrm{CO}$ Complexes of Iron and Ruthenium with the (OC)2M(S-C-C-NH2)2 Fragment. European Journal of Inorganic Chemistry 2012, 2012, 1072-1078.

6. Pascualini, M. E.; Di Russo, N. V.; Thuijs, A. E.; Ozarowski, A.; Stoian, S. A.; Abboud, K. A.; Christou, G.; Veige, A. S. A high-spin square-planar Fe(ii) complex stabilized by a trianionic pincertype ligand and conclusive evidence for retention of geometry and spin state in solution. Chemical Science 2015, 6, 608-612.

7. (a) Evans, D. F. The determination of the paramagnetic susceptibility of substances in solution by nuclear magnetic resonance. Journal of the Chemical Society (Resumed) 1959, 2003-2005. (b) Schubert, E. M. Utilizing the Evans method with a superconducting NMR spectrometer in the undergraduate laboratory. J. Chem. Educ. 1992, 69, 62. 
8. (a) Andersen, R. A.; Faegri, K.; Green, J. C.; Haaland, A.; Lappert, M. F.; Leung, W. P.; Rypdal, K. Synthesis of bis[bis(trimethylsilyl)amido]iron(II). Structure and bonding in $\mathrm{M}[\mathrm{N}(\mathrm{SiMe3}) 2] 2(\mathrm{M}=$ manganese, iron, cobalt): two-coordinate transition-metal amides. Inorganic Chemistry 1988, 27, 1782-1786. (b) Benko, Z.; Burck, S.; Gudat, D.; Nieger, M.; Nyulaszi, L.; Shore, N. Pyrido-annellated diazaphospholenes and phospholenium ions. Dalton Transactions 2008, 4937-4945. (c) Nienkemper, K.; Kehr, G.; Kehr, S.; Fröhlich, R.; Erker, G. (Amidomethyl)pyridine zirconium and hafnium complexes: Synthesis and structural characterization. Journal of Organometallic Chemistry 2008, 693, 1572-1589.

9. Palatinus, L.; Chapuis, G. SUPERFLIP - a computer program for the solution of crystal structures by charge flipping in arbitrary dimensions. Journal of Applied Crystallography 2007, 40, 786-790.

10. Sheldrick, G. A short history of SHELX. Acta Crystallographica Section A 2008, 64, 112-122.

11. Betteridge, P. W.; Carruthers, J. R.; Cooper, R. I.; Prout, K.; Watkin, D. J. CRYSTALS version 12: software for guided crystal structure analysis. Journal of Applied Crystallography 2003, 36, 1487.

12. Schmitz, W. International Tables for X-ray Crystallography, vol. IV (Ergänzungsband). Herausgegeben von der International Union of Crystallography. The Kynoch Press, Birmingham, England, 1974, 366 Seiten einschließlich Tabellen und Sachwortverzeichnis. Kristall und Technik 1975, 10, K120-K120.

13. Cooper, R. I.; Thompson, A. L.; Watkin, D. J. CRYSTALS enhancements: dealing with hydrogen atoms in refinement. Journal of Applied Crystallography 2010, 43, 1100-1107.

14. Sheldrick, G. Sadabs. University of Göttingen, Germany Program for Empirical Absorption Correction of Area Detector Data: 1996.

15. (a) Kahn, O. Molecular magnetism. 1993; p 393. (b) Bain, G. A.; Berry, J. F. DiamagnetiCorrections and Pascal's Constants. J. Chem. Educ. 2008, 85, 532-536.

16. Maurice, R.; Bastardis, R.; Graaf, C. d.; Suaud, N.; Mallah, T.; Guihéry, N. Universal Theoretical Approach to Extract Anisotropic Spin Hamiltonians. Journal of Chemical Theory and Computation 2009, 5, 2977-2984.

17. (a) Malrieu, J. P.; Caballol, R.; Calzado, C. J.; de Graaf, C.; Guihéry, N. Magnetic Interactions in Molecules and Highly Correlated Materials: Physical Content, Analytical Derivation, and Rigorous Extraction of Magnetic Hamiltonians. Chemical Reviews 2014, 114, 429-492. (b) des Cloizeaux, J. Extension d'une formule de Lagrange à des problèmes de valeurs propres. Nuclear Physics 1960, 20, 321-346. (c) Bloch, C. Sur la théorie des perturbations des états liés. Nuclear Physics 1958, 6, 329347.

18. Aquilante, F.; Autschbach, J.; Carlson, R. K.; Chibotaru, L. F.; Delcey, M. G.; De Vico, L.; Fdez. Galván, I.; Ferré, N.; Frutos, L. M.; Gagliardi, L.; Garavelli, M.; Giussani, A.; Hoyer, C. E.; Li Manni, G.; Lischka, H.; Ma, D.; Malmqvist, P. Å.; Müller, T.; Nenov, A.; Olivucci, M.; Pedersen, T. B.; Peng, D.; Plasser, F.; Pritchard, B.; Reiher, M.; Rivalta, I.; Schapiro, I.; Segarra-Martí, J.; Stenrup, M.; Truhlar, D. G.; Ungur, L.; Valentini, A.; Vancoillie, S.; Veryazov, V.; Vysotskiy, V. P.; Weingart, O.; Zapata, F.; Lindh, R. Molcas 8: New capabilities for multiconfigurational quantum chemical calculations across the periodic table. Journal of Computational Chemistry 2016, 37, 506-541.

19. Neese, F. The ORCA program system. Wiley Interdisciplinary Reviews: Computational Molecular Science 2012, 2, 73-78.

20. Andersson, K.; Malmqvist, P. A.; Roos, B. O.; Sadlej, A. J.; Wolinski, K. Second-order perturbation theory with a CASSCF reference function. The Journal of Physical Chemistry 1990, 94, 5483-5488.

21. Angeli, C.; Cimiraglia, R.; Evangelisti, S.; Leininger, T.; Malrieu, J.-P. Introduction of n-electron valence states for multireference perturbation theory. The Journal of Chemical Physics 2001, 114, 10252-10264.

22. (a) Heß, B. A.; Marian, C. M.; Wahlgren, U.; Gropen, O. A mean-field spin-orbit method applicable to correlated wavefunctions. Chemical Physics Letters 1996, 251, 365-371. (b) Malmqvist, P.-Å.; Roos, B. O. The CASSCF state interaction method. Chemical Physics Letters 1989, 155, 189-194. 
23. (a) Roos, B. O.; Lindh, R.; Malmqvist, P.-Å.; Veryazov, V.; Widmark, P.-O. New Relativistic ANO Basis Sets for Transition Metal Atoms. The Journal of Physical Chemistry A 2005, 109, 6575-6579. (b) Widmark, P.-O.; Malmqvist, P.-Å.; Roos, B. O. Density matrix averaged atomic natural orbital (ANO) basis sets for correlated molecular wave functions. Theoretica Chimica Acta 1990, 77, 291-306.

24. (a) Woon, D. E.; Dunning, T. H. Gaussian basis sets for use in correlated molecular calculations. IV. Calculation of static electrical response properties. The Journal of Chemical Physics 1994, 100, 2975-2988. (b) Kendall, R. A.; Dunning, T. H.; Harrison, R. J. Electron affinities of the firstrow atoms revisited. Systematic basis sets and wave functions. The Journal of Chemical Physics 1992, 96, 6796-6806. (c) Dunning, T. H. Gaussian basis sets for use in correlated molecular calculations. I. The atoms boron through neon and hydrogen. The Journal of Chemical Physics 1989, 90, 1007-1023. (d) Woon, D. E.; Dunning, T. H. Gaussian basis sets for use in correlated molecular calculations. III. The atoms aluminum through argon. The Journal of Chemical Physics 1993, 98, 1358-1371.

25. (a) Werncke, C. G.; Bunting, P. C.; Duhayon, C.; Long, J. R.; Bontemps, S.; Sabo-Etienne, S. Two-Coordinate Iron(I) Complex [Fe\{N(SiMe3)2\}2]-: Synthesis, Properties, and Redox Activity. Angewandte Chemie International Edition 2015, 54, 245-248. (b) Desvaux, C.; Amiens, C.; Fejes, P.; Renaud, P.; Respaud, M.; Lecante, P.; Snoeck, E.; Chaudret, B. Multimillimetre-large superlattices of air-stable iron-cobalt nanoparticles. Nature Materials 2005, 4, 750-753. (c) Dumestre, F.; Chaudret, B.; Amiens, C.; Renaud, P.; Fejes, P. Superlattices of Iron Nanocubes Synthesized from Fe[N(SiMe3)2]2. Science 2004, 303, 821-823. (d) Olmstead, M. M.; Power, P. P.; Shoner, S. C. Threecoordinate iron complexes: $x$-ray structural characterization of the iron amide-bridged dimers [Fe(NR2)2]2 ( $\mathrm{R}=\mathrm{SiMe} 3, \mathrm{C} 6 \mathrm{H} 5)$ and the adduct $\mathrm{Fe}[\mathrm{N}(\mathrm{SiMe3}) 2] 2$ (THF) and determination of the association energy of the monomer $\mathrm{Fe}\{\mathrm{N}(\mathrm{SiMe} 3) 2\} 2$ in solution. Inorganic Chemistry 1991, 30, 25472551.

26. (a) Frazier, B. A.; Williams, V. A.; Wolczanski, P. T.; Bart, S. C.; Meyer, K.; Cundari, T. R.; Lobkovsky, E. B. C-C Bond Formation and Related Reactions at the CNC Backbone in (smif)FeX (smif = 1,3-Di-(2-pyridyl)-2-azaallyl): Dimerizations, $3+2$ Cyclization, and Nucleophilic Attack; Transfer Hydrogenations and Alkyne Trimerization $(X=N(T M S) 2$, dpma $=($ Di-(2-pyridyl-methyl)-amide $)$ ). Inorganic Chemistry 2013, 52, 3295-3312. (b) Bartholomew, E. R.; Volpe, E. C.; Wolczanski, P. T.; Lobkovsky, E. B.; Cundari, T. R. Selective Extraction of N2 from Air by Diarylimine Iron Complexes. Journal of the American Chemical Society 2013, 135, 3511-3527. (c) Frazier, B. A.; Wolczanski, P. T.; Lobkovsky, E. B.; Cundari, T. R. Unusual Electronic Features and Reactivity of the Dipyridylazaallyl Ligand: Characterizations of (smif) $2 \mathrm{M}[\mathrm{M}=\mathrm{Fe}, \mathrm{Co}, \mathrm{Co}+\mathrm{Ni}$; smif $=\{(2-\mathrm{py}) \mathrm{CH}\} 2 \mathrm{~N}]$ and [(TMS)2NFe]2(smif)2. Journal of the American Chemical Society 2009, 131, 3428-3429.

27. Llunell, M. C., D.; Cirera, J.; Alemany, P.; Alvarez, S. Shape program, version 2; Universitat de Barcelona: Barcelona, Spain 2010.

28. Chilton, N. F.; Anderson, R. P.; Turner, L. D.; Soncini, A.; Murray, K. S. PHI: A powerful new program for the analysis of anisotropic monomeric and exchange-coupled polynuclear $d$ - and $f$-block complexes. J. Comput. Chem. 2013, 34, 1164-1175.

29. Dekker, C.; Arts, A. F. M.; de Wijn, H. W.; van Duyneveldt, A. J.; Mydosh, J. A. Activated dynamics in a two-dimensional Ising spin glass: Rb2Cu1-xCoxF4. Physical Review B 1989, 40, 1124311251.

30. (a) Marriott, K. E. R.; Bhaskaran, L.; Wilson, C.; Medarde, M.; Ochsenbein, S. T.; Hill, S.; Murrie, M. Pushing the limits of magnetic anisotropy in trigonal bipyramidal Ni(ii). Chemical Science 2015, 6, 6823-6828. (b) Zadrozny, J. M.; Xiao, D. J.; Atanasov, M.; Long, G. J.; Grandjean, F.; Neese, F.; Long, J. R. Magnetic blocking in a linear iron(I) complex. Nat Chem 2013, 5, 577-581. (c) Rechkemmer, Y.; Breitgoff, F. D.; van der Meer, M.; Atanasov, M.; Hakl, M.; Orlita, M.; Neugebauer, P.; Neese, F.; Sarkar, B.; van Slageren, J. A four-coordinate cobalt(II) single-ion magnet with coercivity and a very high energy barrier. Nat Commun 2016, 7, doi:10.1038/ncomms10467. (d) Zadrozny, J. M.; Atanasov, M.; Bryan, A. M.; Lin, C.-Y.; Rekken, B. D.; Power, P. P.; Neese, F.; Long, J. R. Slow magnetization dynamics in a series of two-coordinate iron(ii) complexes. Chemical Science 2013, 4, 125. 
31. Cole, K. S.; Cole, R. H. Dispersion and Absorption in Dielectrics I. Alternating Current Characteristics. J. Chem. Phys. 1941, 9, 341-351.

32. Novikov, V. V.; Pavlov, A. A.; Nelyubina, Y. V.; Boulon, M.-E.; Varzatskii, O. A.; Voloshin, Y. Z.; Winpenny, R. E. P. A Trigonal Prismatic Mononuclear Cobalt(II) Complex Showing Single-Molecule Magnet Behavior. Journal of the American Chemical Society 2015, 137, 9792-9795.

33. Abragam, A.; Bleaney, B. Electron paramagnetic resonance of transition ions. Clarendon P.: 1970.

34. Ziegenbalg, S.; Hornig, D.; Görls, H.; Plass, W. Cobalt(II)-Based Single-lon Magnets with Distorted Pseudotetrahedral [N2O2] Coordination: Experimental and Theoretical Investigations. Inorganic Chemistry 2016, 55, 4047-4058.

35. Carlin, R. L.; Van Duyneveldt, A. J. Magnetic Properties of Transition Metal Compounds. Springer My Copy UK: 1978.

36. Suturina, E. A.; Maganas, D.; Bill, E.; Atanasov, M.; Neese, F. Magneto-Structural Correlations in a Series of Pseudotetrahedral [Coll(XR)4]2- Single Molecule Magnets: An ab Initio Ligand Field Study. Inorganic Chemistry 2015, 54, 9948-9961. 
Table of Contents Graphic and Synopsis

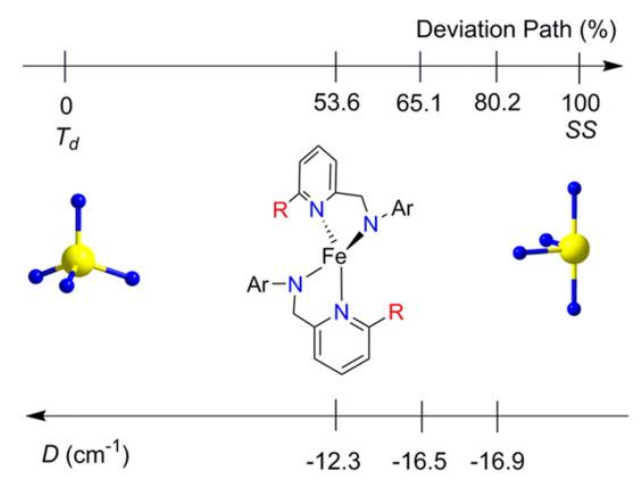

Three new distorted tetrahedral $\mathrm{Fe}^{\mathrm{II}}$ complexes formed with $N, N^{\prime}$-chelating amido-pyridine ligands are shown to exhibit significant magnetic anisotropy and field-induced slow relaxation of magnetization. Ab initio calculations rationalize the impact of structural distortions on both the nature and the magnitude of the magnetic anisotropy $D$ : reduced N-Fe-N bidentate angles are responsible for its negative sign while the torsion angle controls its value. 